\title{
Estudos de alimentação e hábitos alimentares de Schizodon fasciatus Agassiz, 1829, Rhytiodus microlepis Kner, 1859 e Rhytiodus argenteofuscus Kner, 1859, do lago Janauacá - AM. (Osteichthyes, Characoidei, Anostomidae) $\left(^{(*)}\right.$
}

\author{
Geraldo Mendes dos Santos ("*)
}

\begin{abstract}
Resumo
São analisados os hábitos alimentares e a alimentação de três espécies de Anostomidae mais comuns nas "águas brancas" da região de Manaus: Schizodon fasciatus, Rhytiodus microlepis e R. argenteofuscus, em função dos vários estágios de desenvolvimento e dos diferentes níveis d'água regionais na época das coletas. As três espécies são herbivoras, havendo certo grau de preferência determinado pelo tipo e estrutura vegetal ingeridos. Há, possivelmente, uma relação entre a natureza do alimento ingerido, as condições ambientais e certas características do trato digestivo.
\end{abstract}

\section{INTRODUÇÃO}

A família Anostomidae (aracus, piaus, piavussus, piavas, canivetes, solteiras, piaparas, taguaras), endêmica da América do Sul, é constituída por 10 gêneros e cerca de 100 espécies (Géry, 1977). Compreende peixes muito comuns na bacia amazônica e de relevante importância na pesca comercial da região, ocupando, em certas épocas do ano o segundo lugar, em tonelagem, do pescado desembarcado em Manaus e até o primeiro, no Janauacá, local onde os peixes utilizados no presente trabaiho foram coletados (Tabela 1). Além disso, inclui espécies de grande interesse na aquari. cultura (Axelrod et al., 1962) .

Embora a família e os gêneros sejam bem definidos sistematicamente, ainda existem certas dúvidas a nível específico (Géry, 1977) e quase nada se sabe sobre a biologia e ecologia das espécies. Em trabalhos onde aspectos de ecologia de peixes de determinadas áreas da Amazônia são analisados (Lowe-BcConnell, 1964, 1967, 1969, 1975; Marlier, 1967; Knoppel,
1970, 1972; Roberts, 1972; Geisler et al., 1975; Saul, 1975; Goulding, 1979; Soares, 1978) há poucas referências sobre os anostomídeos, inexistindo referências sobre as espécies de Rhytiodus.

O presente trabalho visa a analisar os hábitos alimentares e a alimentação de três espécies de Anostomidae muito abundantes na região de Manaus (Schizodon fasciatus Agassis, 1829; Rhytiodus microlepis Kner, 1859 e Rhytiodus argenteofuscus Kner, 1859) em função das variações dos níveis d'água regional e das diversas fases de desenvolvimento dos indivíduos, procurando averiguar a existência e intensidade de sobreposição alimentar entre as espécies estudadas.

\section{Caracterização da Área de estudo}

As coletas foram feitas no lago Janauacá, situado entre as coordenadas geográficas de $3 .^{\circ} 2$ 'a $3 .^{\circ} 40^{\prime} \mathrm{S}$ e $60^{\circ} 10^{\prime}$ a $60^{\circ} 30^{\prime} \mathrm{W}$, distante cerca de $60 \mathrm{~km}$ de Manaus-Am. (Fig. 1). É um lago de várzea, com profundidade média de 5 a $7 \mathrm{~m}$ e máxima de $12 \mathrm{~m}$, localizado à margem direita do rio Solimões e ligado permanentemente a este através de um canal natural (paraná do Janauacá). Embora chamado de lago, não tem as características deste corpo d'água, como aliás, acontece com quase todos os lagos da Amazônia (Geisler et al., 1975) e apesar de ser uma massa de água contínua, apresenta porções separadas pela "mata de várzea" (Irmler, 1977 apud idem 1978) que são consideradas pelos moradores ribeirinhos como lagos individualizados.

(*) - Parte da tese de Mestrado apresentada ao Curso de Pós-Graduação do INPA/FUA, em 1979.

$(*)$ - Instituto Nacional de Pesquisas da Amazônia, Manaus. 
TABELA 1 - Posição dos "aracus" em relaçăo à captura média mensal de peixes na região de Manaus e no lago Janauacá (entre parênteses), durante 0 ano de 1976. FONTE: Petrere Jr., 1978

\begin{tabular}{|c|c|c|c|c|c|c|c|c|}
\hline \multirow{2}{*}{$\begin{array}{l}\text { Mês } \\
\text { Janeiro }\end{array}$} & \multirow{2}{*}{$\begin{array}{l}\sim \text { Captura } \\
2.73 i, 1\end{array}$} & \multirow{2}{*}{$\begin{array}{r}\text { total }[t] \\
(81,6)\end{array}$} & \multirow{2}{*}{$\begin{array}{c}\text { Captura, de } \\
8,7\end{array}$} & \multirow{2}{*}{$\frac{\text { aracus }(t)}{(1,7)}$} & \multicolumn{2}{|c|}{$\%$} & \multicolumn{2}{|c|}{ Posição } \\
\hline & & & & & 0,32 & $(2,08)$ & $14^{\circ}$ & $\left(8 .^{\circ}\right)$ \\
\hline Fevereiro & 2. 477,2 & $(95,5)$ & 3,9 & $(0,7)$ & 0,16 & $(0,73)$ & $13^{\circ}$ & $\left(10 .^{\circ}\right)$ \\
\hline Março & 2. 140,5 & $(110,7)$ & 8.4 & $(0,3)$ & 0,39 & $(0,27)$ & $13 .^{\circ}$ & $\left(11 .{ }^{\circ}\right)$ \\
\hline Abril & $1.335,0$ & $(64,5)$ & 1,7 & $(0,7)$ & 0,13 & $\{1,08)$ & $15 .^{\circ}$ & $\left(9 .{ }^{\circ}\right)$ \\
\hline Maio & 2.139 .0 & $(99.2)$ & 2,9 & $(0,2)$ & 0,13 & $(0,20)$ & $16 .^{\circ}$ & $\left(12 .^{\circ}\right)$ \\
\hline Junho & $2.657,3$ & $(99,0)$ & 42,3 & - & 1,59 & - & $6 .^{\circ}$ & - \\
\hline Julho & $2.704,9$ & $(87,2)$ & 63,0 & $(16,1)$ & 2,33 & $(18,46)$ & $7 .^{\circ}$ & $\left(2 .^{\circ}\right)$ \\
\hline Agosto & $3.876,1$ & $(125,2)$ & 518,5 & $(58,0)$ & 13,38 & $(46,32)$ & $2 .^{\circ}$ & $\left(1 .^{\circ}\right)$ \\
\hline Setembro & $3.991,2$ & {$[144,1\}$} & 339,6 & $\{22,2]$ & 8.51 & $(15,41)$ & 5. & (2. $\left.{ }^{\circ}\right)$ \\
\hline Outubro & $2.325,1$ & $(138,8)$ & 106,5 & $(29,8)$ & 4,58 & $(21,47)$ & $6 .^{\circ}$ & $\left(2 .^{\circ}\right)$ \\
\hline Novembro & $2.097,8$ & $(131,0)$ & 16,6 & $(7,0)$ & 6,79 & $(5,34)$ & $12 .^{\circ}$ & $\left(3 .{ }^{\circ}\right)$ \\
\hline Dezembro & 2.348 .7 & $(100,7)$ & 0,4 & $(0,2)$ & 0,02 & $(0,19)$ & $21 .^{\circ}$ & $\left(15 .{ }^{\circ}\right)$ \\
\hline TOTAL & $30.829,9$ & $(1.277,5)$ & $1.112,5$ & $(136,9)$ & 3,61 & $(10,72)$ & - & - \\
\hline
\end{tabular}

Por estar próximo a Manaus e pelo fato de o nivel do rio Negro, na sua foz, estar na dependência do nivel dos rios Solimões/Amazonas (uma vez que o fluxo d'água desses é maior que o daquele), consideramos válida a extrapolação das leituras do nível d'água no porto de Manaus ao lago Janauacá, como o fizeram também (Schmidt, 1973) e (Petrere Jr.. 1977).

Os niveis das águas dos grandes rios na região de Manaus têm relação direta com o índice pluviométrico. Segundo Schmidt (1973), o nível máximo das águas dos rios dá-se cerca de um mês após o pico da pluviosidade. Pelos dados apresentados na tabela 2 e fig. 2, a cheia máxima deu-se aproximadamente dois meses após o pico de precipitação.

Apesar de ser um único corpo d'água, mas em virtude de sua enorme extensão, há uma zonação mais ou menos definida (Fig. 3); as águas mais próximas ao Solimões sofrem in fluência direta do rio e apresentam características diferentes daquelas mais afastadas que estão sujeitas às influências das águas de chuva e dos igarapés de terra firme. Nestas últimas, a influência das águas do rio Solimões não se faz sentir diretamente, mesmo por oca- sião da cheia. Na primeira zona, com predomínio de água branca, barrenta, vinda diretamente do Solimōes, abundam os capins aquáticos e é o local mais procurado para as pescarias; na segunda, predominâ ou existe tão somente água vinda de terra firme ou parte daquela do Solimões, já decantada. Sua cor é escura, quase não apresenta vegetação aquática. Na cheia estas águas escuras são empurradas em direção à terra firme pelas águas vindas do rio, através do paraná do Janauacá ou pela várzea; na vazante, com a saída desta para o rio, ela sofre um refluxo, estendendo-se até o meio do lago.

Em virtude dessa zonação e dada a grande extensão do lago, foi escolhida como principal área de estudo a região compreendida entre o Solimões até aproximadamente a metade do lago (área chuleada da figura 1), sujeita às interferências dos dois tipos de água.

\section{MATERIAL E MÉTODOS}

\section{COLETA E TRATAMENTO DAS AMOSTRAS}

As coletas foram feitas quinzenalmente, de abril/77 a abril//78, com a utilização dos dois aparelhos de pesca mais comuns e mais 


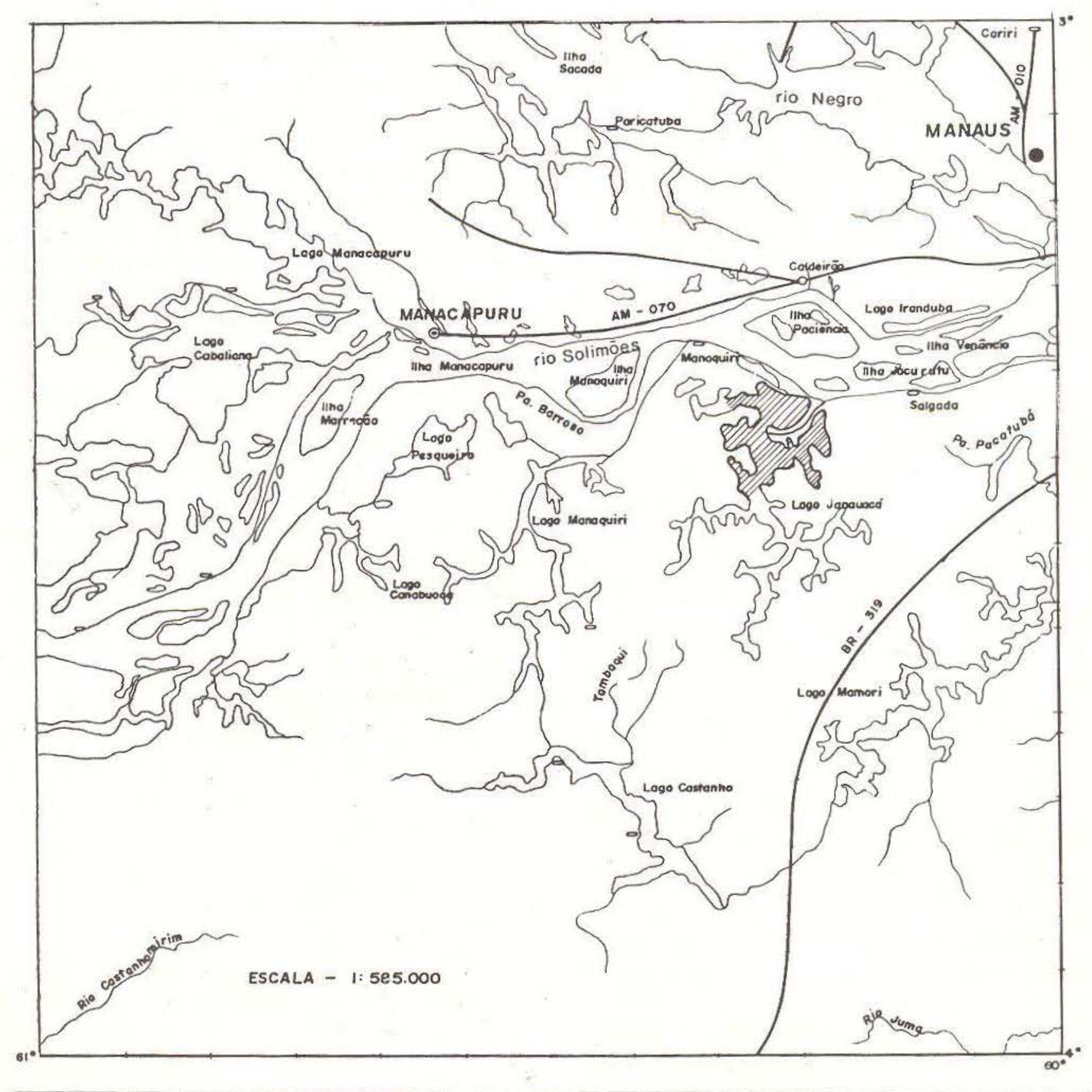

Fig. 1 - Mapa da região de estudo, com indicação da área de coleta (área hachurada).

eficientes da região: a malhadeira e a redinha (Petrere Jr., 1977). As malhadeiras tinham vários tamanhos ( 10 a $50 \mathrm{~m}$ de comprimento e 1,5 a $5,5 \mathrm{~m}$ de altura e malhas variando entre 2 ,a 13 centímetros nó a nó e as redinhas, com comprimento entre 10 a $36 \mathrm{~m}$ e altura de 3 a $12 \mathrm{~m}$ e malhas de 0,5 a $2,0 \mathrm{~cm}$ nó a nó. As redinhas foram usadas com o objetivo de capturar peixes pequenos, principalmente entre os capins aquáticos e nas margens do lago, onde o uso de malhadeiras se torna impraticável.

Todos os peixes foram coletados durante o dia, até aproximadamente às 20:00 horas. Muitas tentativas foram feitas para coleta de material durante a noite (das 20:00 horas em diante) mas pouquíssimos exemplares foram coletados (apenas quatro, durante três noites de trabalho). Este fato sugere que os anosto- 
TABELA 2 - Valores mensais médios do nível das águas do rio Negro acima do nível do mar e da precipitação pluviométrica na regiâo de Manaus, de abril de 1977 a abril de 1978. FONTE: Administração do Porto de Manaus e Serviço de Meteorologia do INPA, respectivamente

\begin{tabular}{llc}
\hline Mês & $\begin{array}{c}\text { Nivel do Rio } \\
(\mathrm{m})\end{array}$ & $\begin{array}{c}\text { Precipitação } \\
\text { Pluviométrica(mm) }\end{array}$ \\
\hline Abril & 25,53 & 391,2 \\
Maio & 27,39 & 267,8 \\
Junho & $28,33-28,45^{*}$ & 98,4 \\
Julho & 28,25 & 79,9 \\
Agosto & 26,72 & 23,0 \\
Setembro & 23,41 & 165,8 \\
Outubro & $20,83-20,66^{\circ *}$ & 275,8 \\
Novembro & 21,61 & 149,6 \\
Dezembro & 22,32 & 262,4 \\
Janeiro & 23,40 & 277,9 \\
Fevereiro & 23,44 & 218,5 \\
Março & 24,34 & 366,6 \\
Abril & 25,63 & 334,1 \\
\hline
\end{tabular}

(*) - máxima, dia 28/06/77

(**) - minimo, dio $14 / 10 / 77$

mídeos, como os Characoidei em geral (LoweMcConnel, 1964; Roberts, 1972 e Geisler et al., 1975) tem hábitos diurnos e portanto, durante o dia, encontram-se espalhados pelo lago, quando são mais facilmente capturados .

Inicialmente, para análise dos dados morfométricos e merísticos, os peixes foram numerados, medidos, pesados e formolizados (formol a $8 \%$ ) e levados ao laboratório, na sede do INPA. Após o segundo mês de coleta os peixes capturados foram numerados, medidos, pesados, eviscerados e feito o registro dos estádios gonadais, no campo. As vísceras retiradas foram formolizadas em fras$\cos$ individualizados e levadas ao laboratório para posterior estudo.

No laboratório, os peixes foram deixados em formol por cerca de dois meses e em seguida lavados em água corrente durante aproximadamente duas horas e colocados em ál$\mathrm{cool}$ a $70 \%$. Parte deste material serviu para o estudo dos caracteres que exigem exemplares conservados e inteiros e outra foi usada para os demais fins. As visceras formolizadas, após o tempo mínimo de um mês, foram lavadas em água corrente durante cerca de dez minutos e colocadas em áleool a $70 \%$. Posteriormente o intestino e o estômago foram medidos separadamente e contados os cecos pilóricos. Os estômagos foram abertos e feita uma estimativa do grau de enchimento. Os conteúdos estomacais foram colocados em ál$\mathrm{cool}$ a $70 \%$ em placa de Petri e analisados com auxilio de lupa estereoscópica e microscópio.

\section{AVALIAÇÃO DA ALIMENTAÇÃo}

$\mathrm{Na}$ avaliação do grau de enchimento dos estômagos, para cada classe de enchimento ou repleção, foi atribuído um determinado grau e a cada um destes foram atribuídos pontos, de acordo com Knoppel (1970) e Haram et al. (1971), como está indicado na Tabela 3.

Para a quantificação dos graus de repleção, foi adotado o grau médio de repleçăo (Gr), calculado segundo a expressão:

$$
\mathrm{Gr}=\frac{\sum \mathrm{i} \cdot \mathrm{fa}}{\sum \mathrm{fa}}
$$

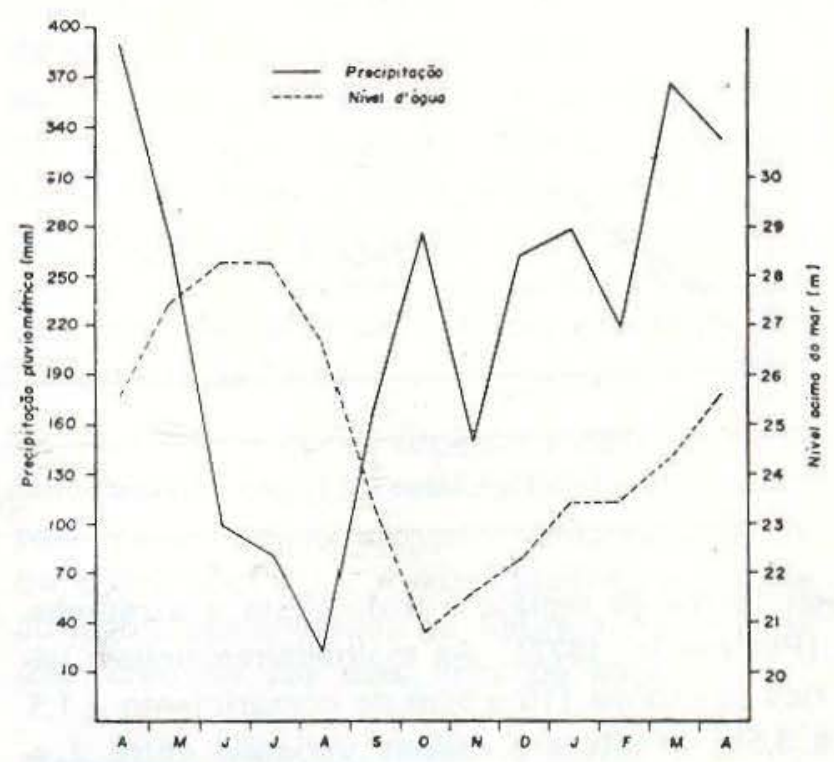

Fig. 2 - Valores médios mensais do nivel d'água do rio Negro acima do nivel do mar e da precipitação pluviométrica nos arredores de Manaus, durante o período de estudo, de abril/77 a abril/78. FONTE: Administração do Porto de Manaus e Estação Meteorológica do INPA, respectivamente. 


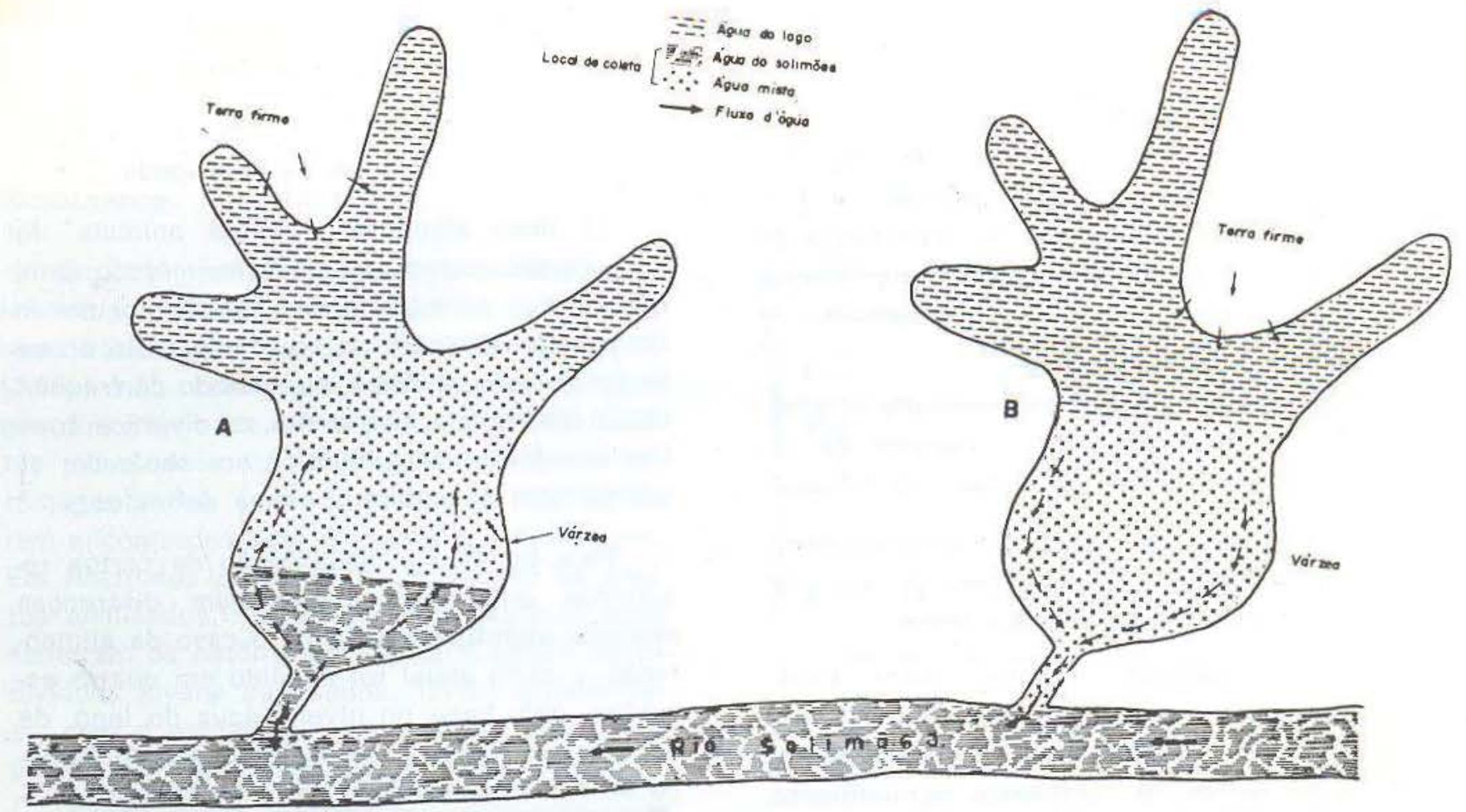

Fig. 3 - Esquema simplificado do fluxo d'água no Lago Janauacá na época de cheia (A) e vazante (B).

onde " $\mathrm{i}$ " = grau de repleção atribuído (pontos), " $\mathrm{fa}$ " = freqüência absoluta de indivíduos com grau " $i$ " de repleção.

Para a análise dos ítens alimentares, adotou-se um método qualitativo (freqüência de ocorrência) e outro quantitativo ou semi-quantitativo (Método dos pontos), proposto por Swynnerton \& Whorthington (1940) os quais, segundo a revisão feita por Hynes (1950) e comentada por Corbert (1961) são os mais práti$\cos$ e adequados.

A freqüência de ocorrência foi considerada como a dos ítens determinados em relação ao número de estômagos analisados, contendo alimento. No método dos pontos, para cada freqüência relativa dos itens encontrados (até cerca de $10 \%, 1 / 4,2 / 4,3 / 4$ e $4 / 4$ cheios) foram atribuídos os graus e os pontos correspondentes, de acordo com os dados da tabela anteriormente citada; semelhantemente foi adotada a mesma expressão usada para o cálculo do $\mathrm{Gr}$, sendo o valor de cada ítem (fo) $=$ $\sum i$. fa

$$
\sum \mathrm{fa} \text {, sendo " } \mathrm{i} \text { " o grau atribuído (pontos) }
$$

TABELA 3 - Escala de pontos para estimação do estádio e do grau de repleçäo dos estômagos das espécies estudadas

\begin{tabular}{lcc}
\hline Estádio de repleção & Grau de repleçäo & Pontos \\
\hline Vazio & O & 0 \\
Traços (até 10\%) & A & 0,5 \\
1/4 cheio & B & 1 \\
$2 / 4$ cheio & C & 2 \\
$3 / 4$ dheio & D & 3 \\
$4 / 4$ cheio & E & 4 \\
\hline
\end{tabular}

e "fa", a freqüência absoluta dos ítens considerados com o grau " $i$ ".

Os ítens alimentares encontrados são definidos e listados, na ordem em que são citados nas tabelas e gráficos, como se segue:

Raiz: praticamente só raízes de gramíneas aquáticas flutuantes, possivelmente Paspalum repens, um dos capins que permanece fixo ao substrato com o nível de água baixo, mas passa a maior parte de seu ciclo de vida flutuan- 
do. E o capim mais abundante no lago. Freqüentemente, verifica-se a "poda" de suas raizes, face, talvez, à ação dos peixes.

Algas: geralmente filamentosas, aderidas às raízes ou folha-caule das gramíneas. Predominaram as Chlorophyta. $\mathrm{Na}_{\mathrm{a}}$ freqüência de ocorrência, foram reconhecidas e consideradas separadamente: Chlorophyta, Chrisophyta e Cianophyta.

Folha-caule: quase exclusivamente originários de gramíneas aquáticas. Geralmente foram encontradas partes do limbo e da bainha.

Restos vegetais: material semi-digerido, representado pelos restos de plantas não gramineas, principalmente folhas e flores.

Restos orgânicos: material quase totalmente digerido, de origem vegetal ou animal, mas de difícil identificação; possivelmente, trata-se de restos de alimentos normalmente encontrados nos estômagos em fase avançada de digestão.

Fruto-Semente: representados quase totalmente por Cecropia sp. e Gramineae.

"Coarse-litter": pedaços te madeira ou vegetais secos

Restos animais

Quironomídeos: principalmente larvas e algumas pupas.

Micro-crustáceos: Ostracoda principalmente e Cladocera.

Ovos: ovos diminutos, da forma oval, possivelmente de Nemathelminthes e outros maiores, redondos, envoltos e aderidos por uma massa gelatinosa e elástica, possivelmente, de artrópodos.

Esponja: representada por espículas cilíndricas, de extremidades pontiagudas, brancas, microscópicas e restos de colônias, possivelmente de Spongilidae, principal família de Poriphora de água doce da região.

Outros artrópodos: pedaços do corpo de insetos e aranhas
Rotiferos: constituidos basicamente por espécies de Keratella.

Moluscos: constituídos principalmente por conchas de Pelecipoda.

O ítem alimentar "Restos animais" foi considerado como um todo no método semiquantitativo ou método dos pontos, por ser ínfima a percentagem do volume por ele ocunado em relação ao total. No método de frequeência de ocorrência, entretanto, os diversos constituintes foram considerados em separado, de acordo com os subítens acima definidos.

Para facilitar a visualização de certos resultados que não apresentarem diferenças mensais significantes, como o caso da alimentação, o ciclo anual foi dividido em quatro estações, com base no nível d'água do lago, de acordo com os resultados obtidos pelo Serviço de Administração do Porto de Manaus. Assim, fica sendo como a estação ou nível "elevado", os meses de maio, junho e julho; como estação "abaixando", agosto e setembro; como estação "baixa", outubro, novembro e dezembro e como estação "elevando", os meses de janeiro, fevereiro, março e abril.

$\mathrm{Na}$ tentativa de estimar-se o grau da superposição da dieta alimentar entre as três espécies, empregamos o método numérico de Morisita (1959, apud Zaret, 1971) na forma de coeficiente de sobreposição, assim calculado:

$$
C \lambda=\frac{2 \cdot \sum_{i=1}^{S} X i}{\sum_{i=1}^{S} X i^{2}} \frac{Y i}{S} \text { onde, }
$$

$S=$ número total das categorias de alimento; $\mathrm{Xi}-\mathrm{Yi}=$ frequeência relativa dos ítens alimentares (i) das espécies $X, Y$.

$C \lambda$ varia então de zero (quando não há categorias de alimento em comum) a um (quando as categorias são totalmente comuns às espécies consideradas). Para estes cálculos, usamos as freqüências relativas dos alimentos constantes das tabelas $n^{\circ} 5$ e 8 sendo 
que os valores absolutos dos subitens de origem animal foram somados e tratados como pertencentes à categoria "Restos Animais".

\section{Resultados}

Em 281 indivíduos adultos de Schizodon fasciatus analisados, $100(35,6 \%)$ apresentaram estômagos vazios; em 102 jovens, 4 (3,9\%) não continham alimento nos estômagos. Em Rhytiodus microlepis, dentre 180 adultos examinados, $35(19,4 \%)$ apresentaram estômagos vazios e em 56 jovens, $6(10,7 \%)$ foram encontrados sem alimento nos estômagos. Em Rhytiodus argenteofuscus, dentre 44 adultos analisados, 20 exemplares $(45,5 \%)$ apresentaram os estômagos vazios e dentre 10 indivíduos jovens analisados, $1(1 \%)$ apresentouse com o estômago vazio. Esses resultados podem ser visualizados na tabela 4 .

Esses dados indicam que a percentagem de estômagos vazios é muito maior nos adultos do que nos jovens, nas três espécies estudadas. Observa-se o mesmo fenômeno com relação ao grau médio de repleção do estômago $(\bar{G}$ r). Os valores da tabela 4 e figuras 4 revelam que em $S$. fasciatus o índice obtido para os adultos $(1,54)$ é menor que para os jovens $(2,52)$; o mesmo ocorre com $R$. microlepis (1,89 para adultos e 2,87 para jovens) e com R. argenteofuscus $\{1,13$ para adultos e 3,30 para jovens). Os valores dos graus médios de repleção para jovens e adultos das três espécies, por estação, mostram que os adultos de $S$. fasciatus e $R$. microlepis apresentam maiores valores $(2,08$ e 2,45 , respectivamente) na estação "baixa" e menores valores $(1,12 \mathrm{e}$ 1,58 , respectivamente) na estação "elevando". $R$. argenteofuscus apresentou maior valor $(2,80)$ na estaçăo "alta" e menor $(0,11)$ na estação "baixa". Os jovens das três espécies apresentaram maiores valores na estação "elevando" (3,15 para S. fasciatus, 3,48 para $R$. microlepis e 3,55 para $R$. argenteofuscus.

Os resultados da análise qualitativa (freqüência de ocorrência) e semi-quantitativa (método dos pontos), em relação às estaçōes ou níveis de água do rio, acham-se nas tabelas 5 e 6 e figuras 5 e 6 .
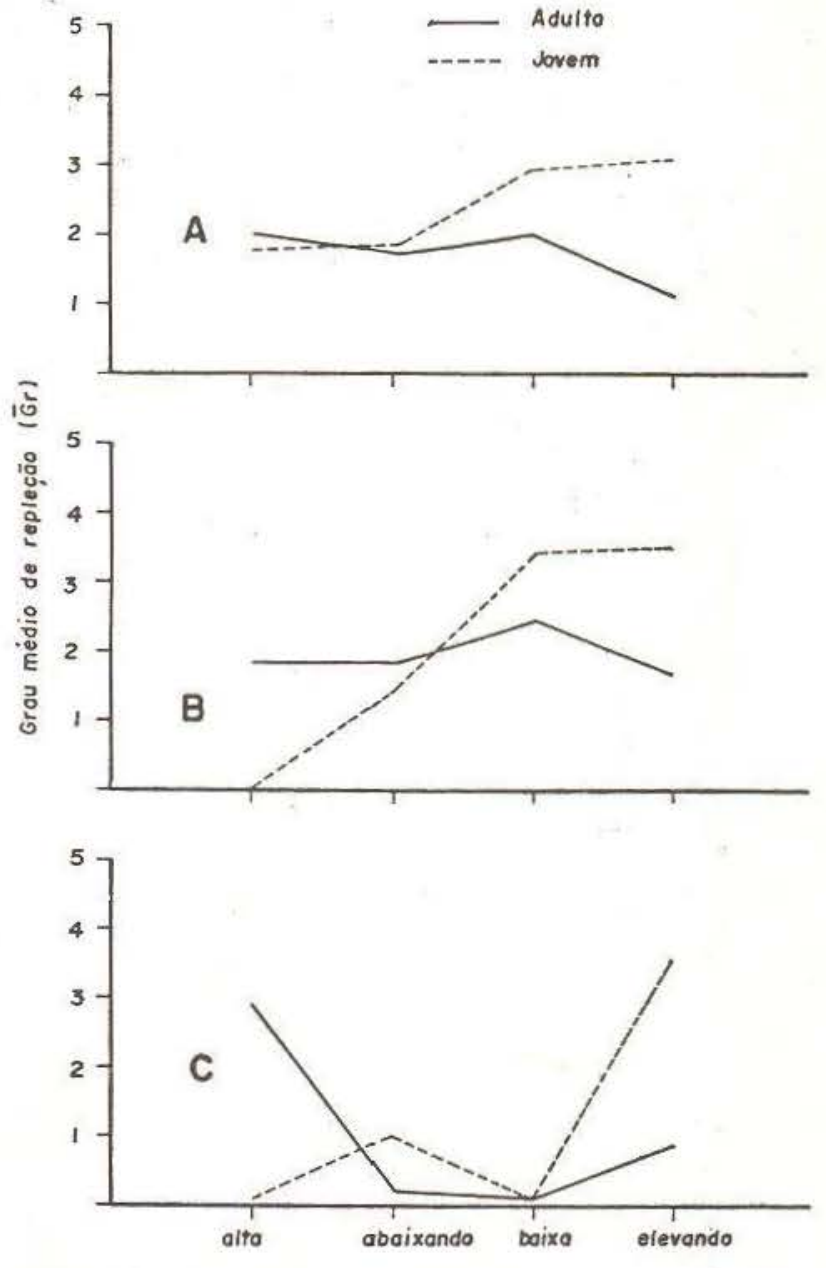

Fig. 4- Graus médios de repleçäo (Gr) dos individuos jovens e adultos de Schizodon fasciatus (A), Rhytiodus microlepis $(B)$ e Rhytiodus argenteofuscus $(C)$, nas quatro estações estabelecidas.

O método dos pontớs, além de indicar a presença dos ítens, $\epsilon$ stima também seus volumes relativos e por isto foi utilizado para a comparação das freqüências relativas dos ítens alimentares.

Os ítens mais freqüentes, em percentagem decrescente, por estação, foram:

\section{Schizodon fasciatus:}

Estação "alta" — folha-caule, fruto-semente, algas e raízes. Iha-caule.

Estação "abaixando" — algas, raízes, fo-

Estação "baixa" - raízes, folha-caule, restos vegetais, algas. 
TABELA 4 - Freqüências absoluta e reletiva dos graus de repleção e dos graus médios de repleção (Gr) de jovens e adultos das espécies estudadas

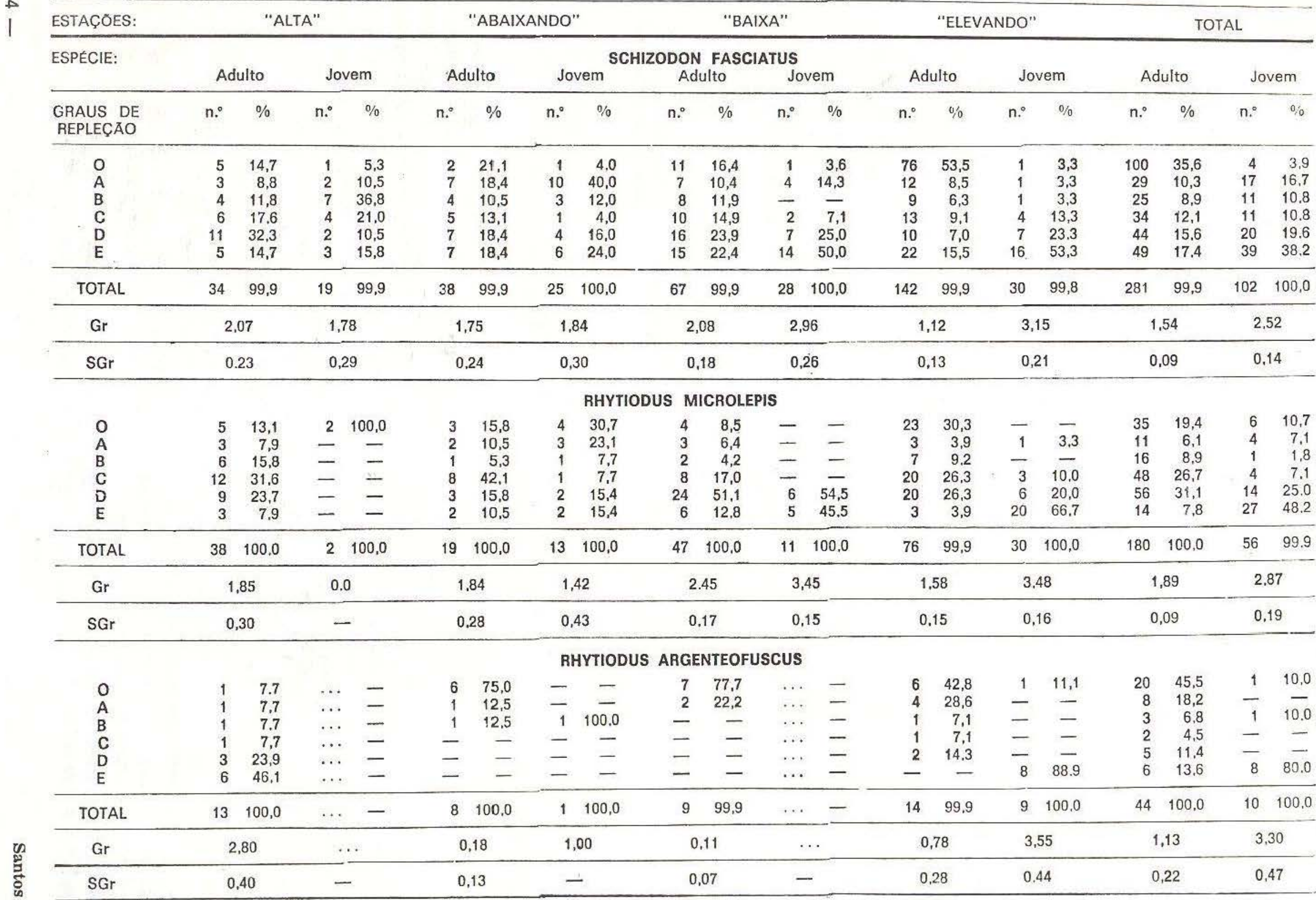




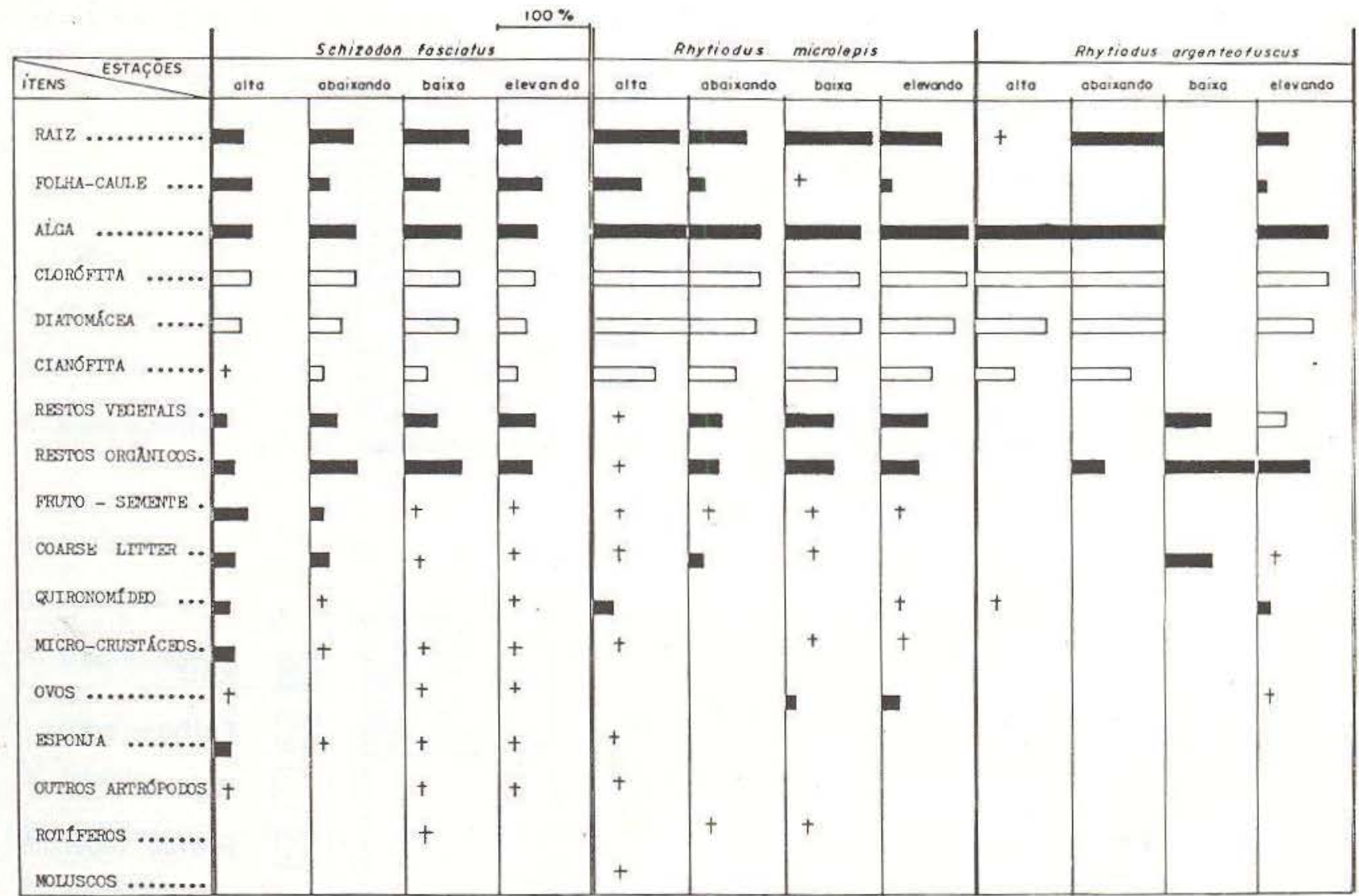

Fig. 5 - Composição percentual dos ítens alimentares das três espécies, calculada através do método de freqüência de ocorrência, para as quatro estações estabelecidas. O sinal $(+)$ representa valores abaixo de $10 \%$; as barras cla. ras, os constituintes do item algas.

Estação "elevando" — folha-caule, algas restos vegetais.

\section{Rhytiodus microlepis}

Estação "alta" — raízes, algas folha-caule Estação "abaixando" — algas, raízes

Estação "baixa" — raízes, algas, restos vegetais

Estação "baixa" - raízes, algas, restos tos vegetais.

\section{Rhytiodus argenteofuscus}

$$
\begin{aligned}
& \text { Estação "alta" - algas, raízes } \\
& \text { Estação "abaixando" - algas, raízes } \\
& \text { Estação "baixa" - restos orgânicos, res- } \\
& \text { tos vegetais, "coarse } \\
& \text { litter". }
\end{aligned}
$$

$$
\begin{aligned}
\text { Estação "elevando" - } & \text { algas, restos orgâ- } \\
& \text { nicos, restos ve- } \\
& \text { getais. }
\end{aligned}
$$

Os valores dos coeficientes de sobreposição alimentar, para as três espécies, calculados para as quatro estações estabelecidas: variaram de 0,08 a 0,96 e são apresentados na tabela 7 .

Os resultados da análise qualitativa (freqüência de ocorrência) e semi-quantitativa (método dos pontos), em relação às diferentes classes de tamanho dos indivíduos das três espécies, acham-se nas tabelas 8,9 e figuras 7,8 .

Os itens mais freqüentes, em percentagem decrescente, por classe de tamanho foram:

\section{Schizodon fasciatus}

Classe de 20 a $100 \mathrm{~mm}$ : algas, restos orgânicos. 


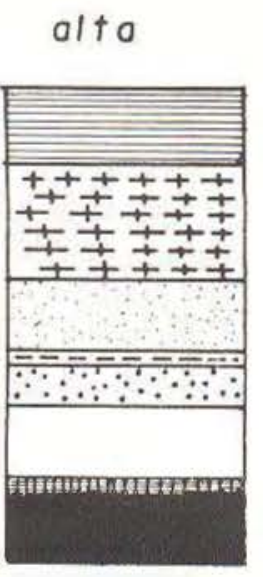

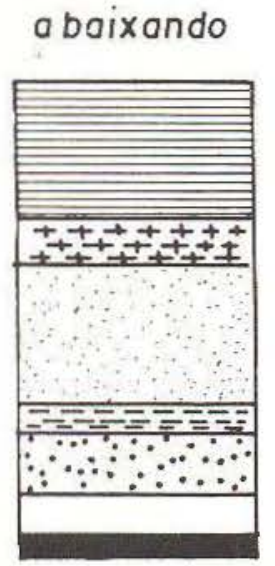

baixa

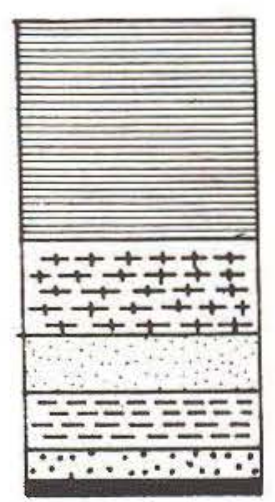

Schizodon fasciatus
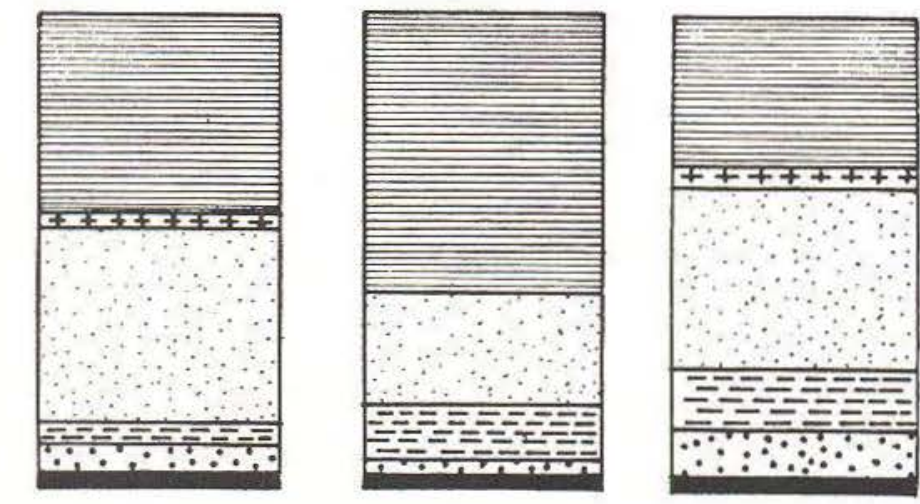

Rhytiodus microlepis

elevando

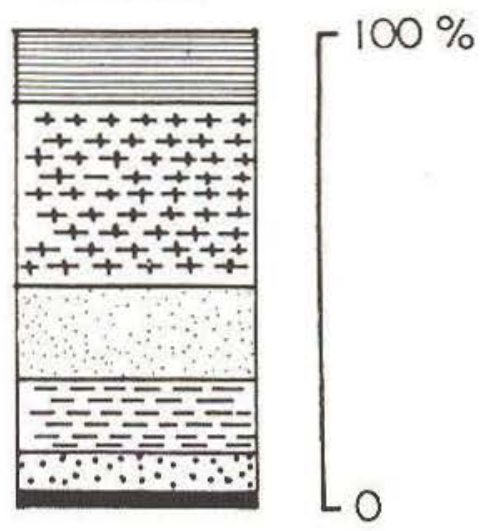

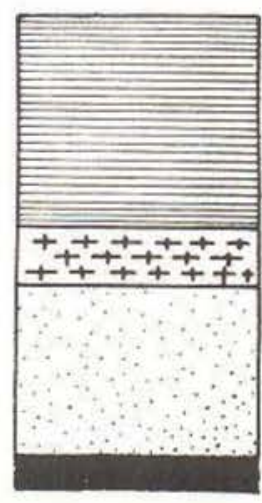
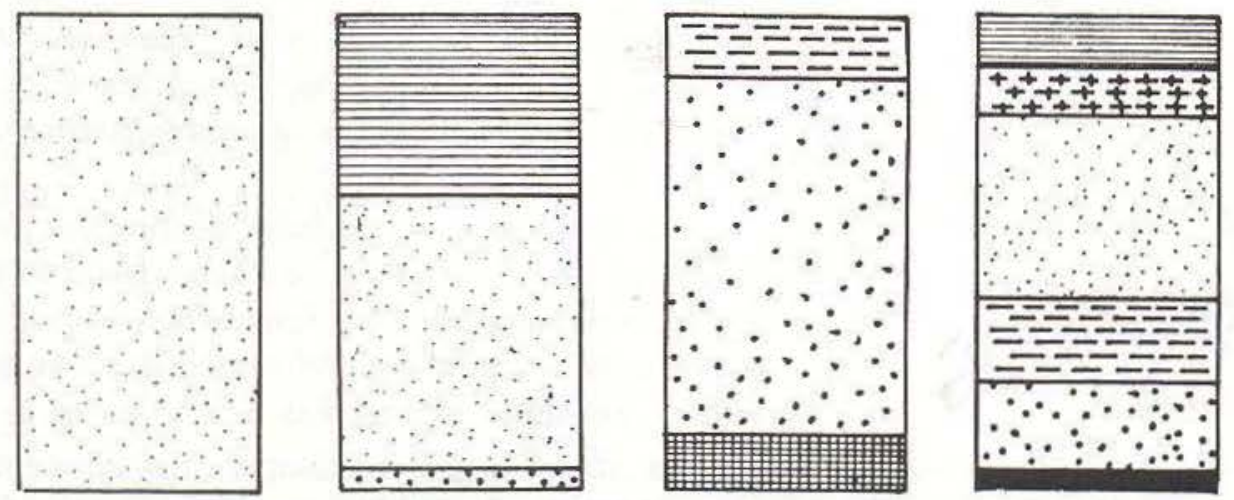

$\therefore$

Restos orgānicos

Coarse litter

Fruto-semente

Restos onimois

\section{Rhytiodus argenteofuscus}

Fig. 6 - Freqüência relativa dos ítens alimentares das três espécies, nas estações estabelecidas, caiculada através do método dos pontos. 
TABELA 7 - Coeficientes de sobreposição alimentar, calculados para as espécies estudadas, nas diferentes faixas de tamanho e estações estabelecidas

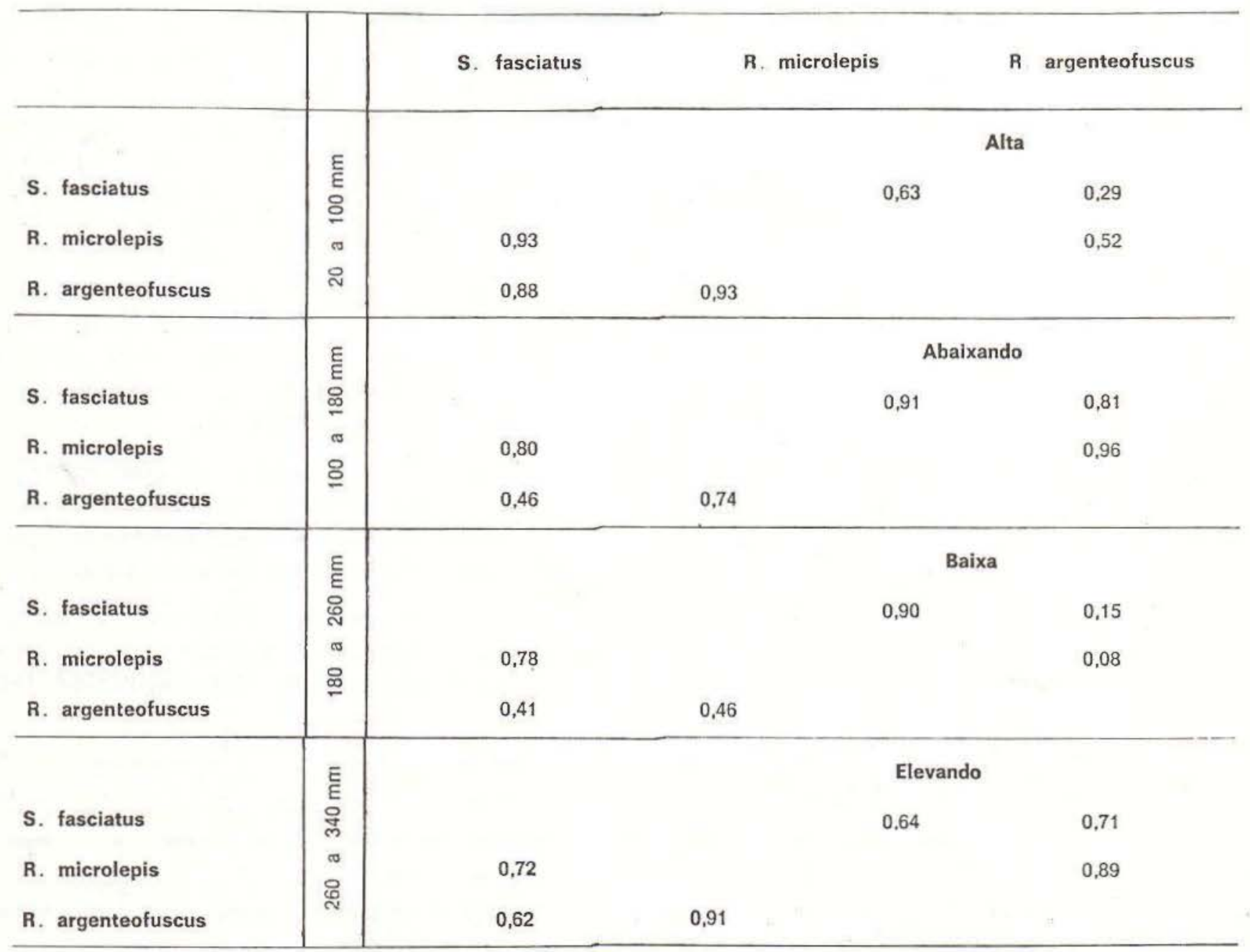

Classe de 100 a $180 \mathrm{~mm}$ : raizes, algas, foIha-caule.

Classe de 180 a $260 \mathrm{~mm}$ : raizes, folhacaule, algas.

Classe de 260 a $340 \mathrm{~mm}$ : folha-caule, raizes, restos vegetais.

Rhytiodus microlepis

Classe de 20 a $100 \mathrm{~mm}$ : algas. restos vegetais, restos orgânicos.

Classe de 100 a $180 \mathrm{~mm}$ : algas, raízes, restos orgânicos.
Classe de 180 a $260 \mathrm{~mm}$ : raízes, algas.

Classe de 260 a $340 \mathrm{~mm}$ : raízes, algas.

Classe de 340 a $420 \mathrm{~mm}$ : raízes, algas.

Rhytiodus argenteofuscus

Classe de 20 a $100 \mathrm{~mm}$ : algas, restos orgânicos

Classe de 100 a $180 \mathrm{~mm}$ : algas, raízes

Classe de 180 a $260 \mathrm{~mm}$ : algas, restos orgânicos

Classe de 260 a $340 \mathrm{~mm}$ : algas, raizes, restos vegetais.

Estudos... 
Os valores dos coeficientes de sobreposição alimentar, calcuiados para as tres espécies, nas diferentes classes de comprimento variaram de 0.41 a 0.93 e sāo apresentados na tabela 7.

\section{DISCUSSÃO E CONCLUSÕES}

Os adultos das espécies estudadas tiveveram um grau médio de repleção mais elevado na estação que antecede ao processo de desova, ou seja, maior Gr na estação "baixa". Este fenômeno não ocorreu somente em $R$, argenteofuscus, onde o maior $\mathrm{Gr}$ se deu na es. tação "elevando". Parece todavia (de acordo com outras evidencias) que o resultado mais coerente seja aquele apresentado pelas outras duas espécies, uma vez que o resultado obtido em relação a $R$. argenteofuscus seja possivelmente uma decorrência do pequeno número de espécimes amostrados. Observou-se ainda que ao mais baixo grau médio de repleção, correspondeu o mais elevado grau médio de ma: turação gonadal (cf. Santos, 1979).
Evidencia-se assim que por ocasiāo da de. sova é reduzida a atividade alimentar das es. pécies. Por outro lado, a elevada quantidade de gordura armazenada na cavidade abdominal, revestindo todas as visceras, observado nas estações "abaixando" e "baixa" reforçam a idéia de que nessas estaçōes os peixes dispõem de abundante alimento ou tem grande atividade alimentar e que ai se preparam, ar. mazenando reservas nutritivas, para a elaboração e maturação dos produtos sexuais. Os jovens, por outro lado, sem passar pelos processos e alterações decorrentes dos ciclos de maturação gonadal, mostraram-se mais homogêneos quanto ao grau médio de repleção que os adultos correspondentes.

As maiores variações do grau médio de repleção dos estômagos nos adultos parecem estar mais ligados ao desenvolvimento gonadal que à variação das fontes alimentares.

Para os peixes amazônicos, a estação "baixa", chamada de estação seca ou verāo, é considerada por Lowe-McConnell (1964, 1967.

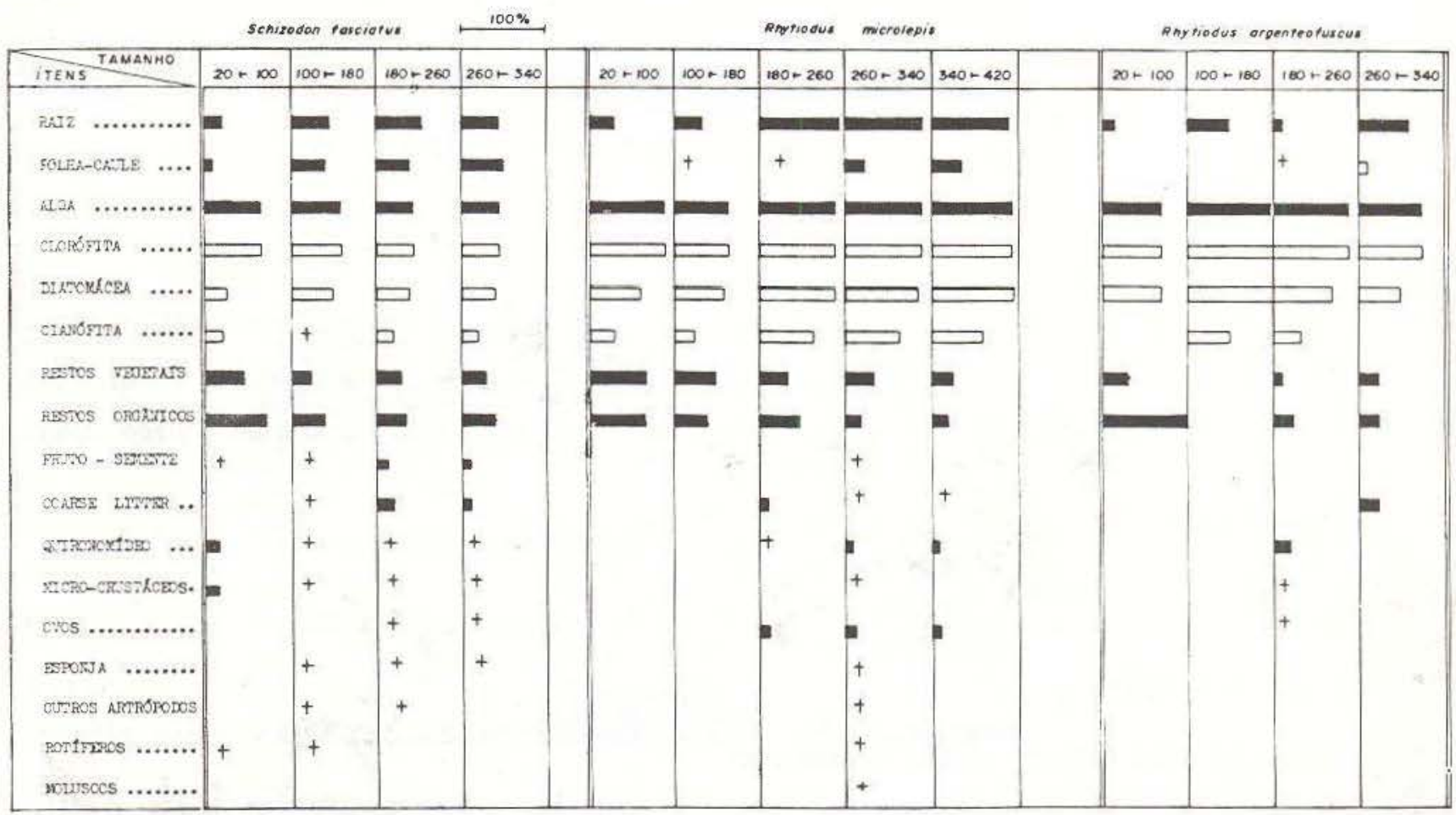

Fig. 7 - Composição percentual dos ítens alimentares das três espécies, calculada através do método de freqũência de ocorrência, para as classes de tamanho indicadas. O sinal $(+)$ representa valores abaixo de $10 \%$; as barras claras, os constituintes do item algas. 

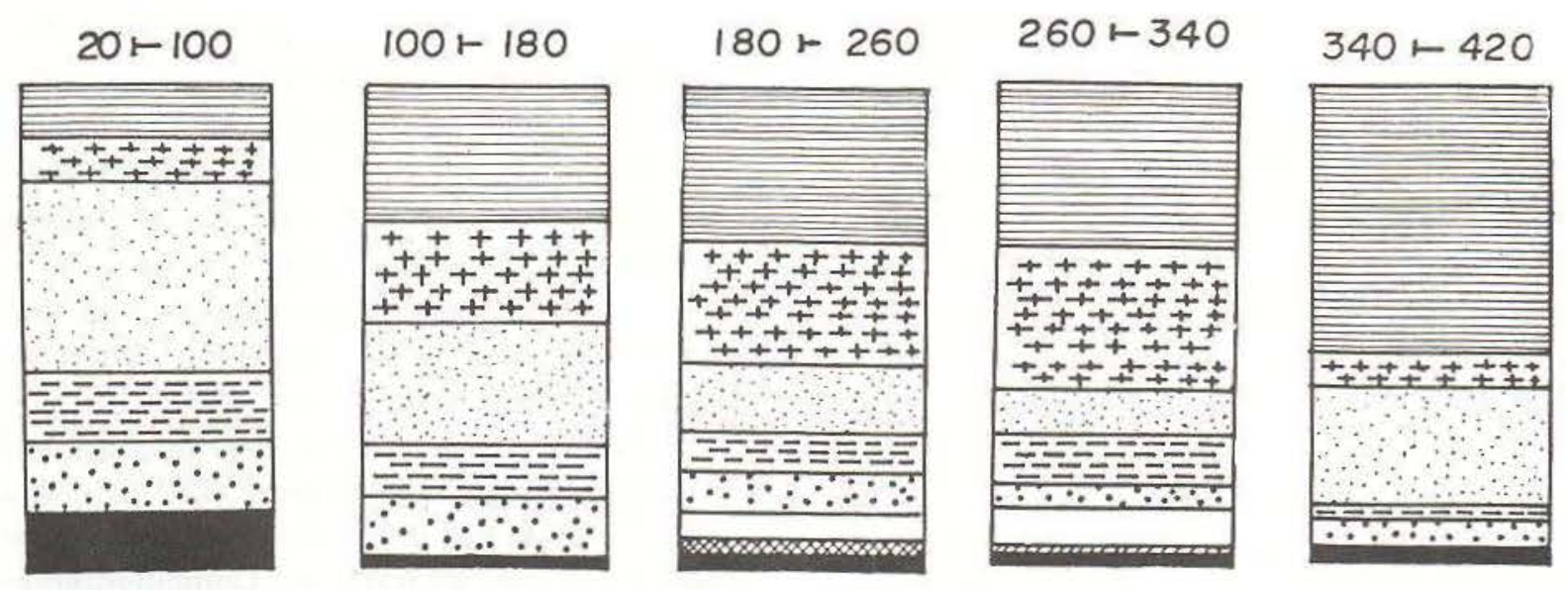

\section{Schizodon fasciatus}
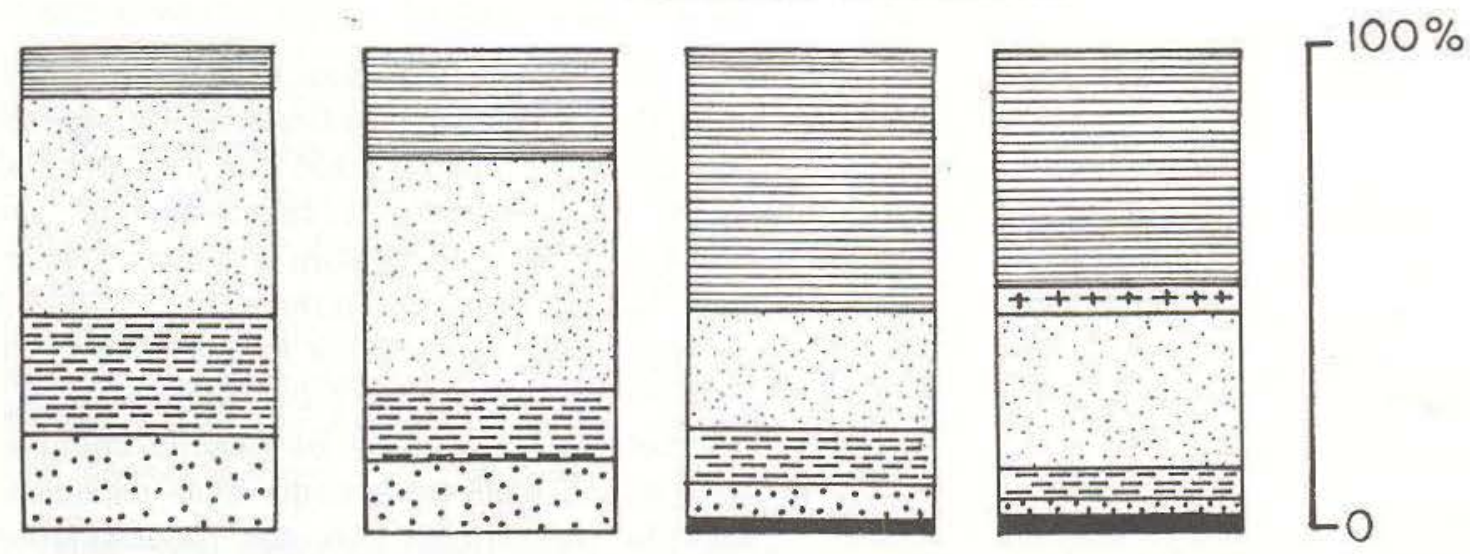

\section{Rhytiodus}
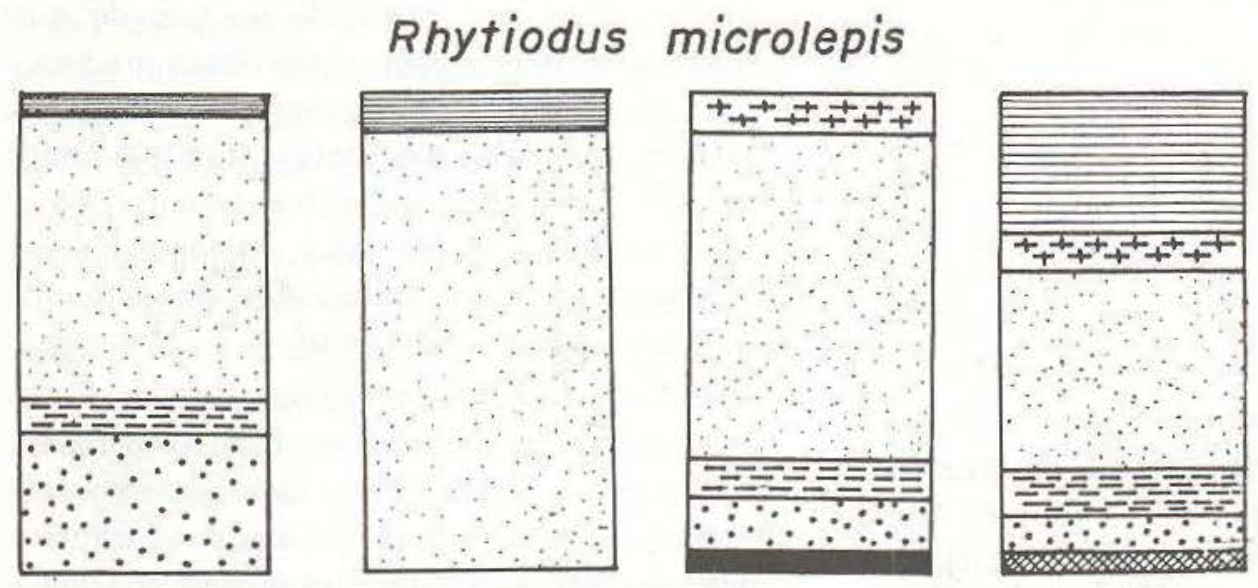

Raiz

Folha - caule

Alga

Restos vegetais

$\because:$ Restos orgânicos

Coarse litter

Fruto-semente

\section{Rhytiodus argenteofuscus}

Restos animais

Fig. 8 - Frequeência relativa dos ítens alimentares das três espécies, nas classes de tamanho indicadas, calculada pelo método dos pontos.

1969) como a época de diminuição da oferta alimentar. Para esta autora, nessa época, com a volta das águas fluviais ao leito normal, baixando seu nível de 8 a 11 metros, ocorre o desaparecimento das áreas alagadas, fato que causa um aumento da densidade de peixes, da competição e da superposição dos hábitos alimentares entre as espécies. Zaret (1971), por outro lado, trabalhando com peixes do Panamá, chegou às mesmas conclusões, exceto com relação à sobreposição alimentar. Para ele, a sobreposição é menor na estação baixa pois

Estudos... 
os peixes aí teriam que recorrer mais forçosamente às suas especializaçōes ou a biótopos menos amplos, já que as fontes de alimento e o próprio alimento diminuem nesta estação. Por outro lado, Myers (1963 apud Lowe-McConnell 1969) afirma que para os peixes herbivoros generalizados dificilmente o alimento é um fator limitante.

As espécies aqui tratadas podem ser consideradas como herbivoras generalizadas e, pelo fato de terem sido estudadas num período onde as variações do nível d'água $(7,76 \mathrm{~m})$ e das delas decorrentes estão abaixo do normal. fica difícil uma comparação direta ou uma conclusão decisiva a respeito daquelas hipóteses; entretanto, pelas análises e consideraçōes das tendências alimentares adiante apresentadas, há indicações de que a sobreposição alimentar é realmente maior na época da vazante.

Com relação à natureza dos itens alimentares, Schizodon fasciatus mostrou preferências, em ordem de importância, pelas raizes, folha-caule e algas, Rhytiodus microlepis, por raizes e algas e $R$. argenteofuscus, por algas, restos orgânicos e raízes.

Nas estações "abaixando" e "baixa", quando a grande massa de capins aquáticos flutuantes já maduros e secos é lançada do lago para o rio (caso de Paspalum repens, Oriza $\mathrm{sp}$., etc.) ou morta e coberta pela água (caso de Paspalum fasciculatum), Schizodon fasciatus alimentou-se mais intensamente de raizes, havendo em conseqüência um elevado coeficiente de sobreposição alimentar com R. microlepis $(0,91$ e 0,90 , respectivamente). Nas estações "alta" e "elevando", por outro lado, em que há um predomínio de capins aquáticos verdes e tenros, mormente de $P$. repens, que parece ser o principal constituinte deste ítem, S. fasciatus passou a tomá-los mais intensamente, havendo um menor coeficiente de sobreposição alimentar com $R$. microlepis $(0,63$ e 0,64 , respectivamente). Ainda para $S$. fasciatus foi grande a frequeência dos ítens "fruto-semente" e "restos-animais" na estação "alta". Nesta época, a água adentra-se nas matas, ilhas, penínsulas'e restringas e muitas árvores do igapó estăo frutificando, como
Cecropia sp. cujos frutos e sementes constituem o principal item dos conteúdos estomacais juntamente com as sementes de Gramineae. Observou-se que sementes inteiras ocorrem por todo o trato digestivo dessas espécies, o que reforça a idéia de que possivelmente, esses peixes sejam agentes de dispersão para essas plantas, comuns nos ambientes aquáticos das várzeas amazônicas. Em $S$. fasciatus, o item "restos animais" foi representado principalmente por esponjas, que aparecem comumente junto ao ítem "coarse litter", aderidas à sua superficie. Coincidentemente, - "coarse-litter" ocorre em maior percentagem também nesta estação.

Com relação às duas espécies de Rhytiodus, foram altos os coeficientes de sobreposição alimentar $(0,96$ e 0,89$)$ nas estaçōes "abaixando" e "elevando", respectivamente, sendo algas o ítem mais comum a ambas. Na estação "alta", este coeficiente foi baixo $(0,52)$, principalmente porque em $R$. microlepis o íten raiz ocorreu em maior freqüência e em $R$. argenteofuscus, algas. O baixíssimo coeficiente de sobreposição entre estas duas espécies na estação baixa $(0,08)$ não nos pareceu conclusivo e deve ser atribuído ao fato de que $R$. microlepis teve raizes como item predominante e $R$. argenteofuscus, restos orgânicos que podem ter derivado do(s) ítem(s) citado(s) para R. microlepis. Contrariamente ao que ocorreu com $S$. fasciatus, foi pequena a percentagem do item folha-caule na alimentação das espécies de Rhytiodus.

Ainda em $R$. microlepis, raízes e algas ocorreram em proporções bem próximas, em todas as estações. Este fato pode ser considerado normal porque as algas encontram-se aderidas às raízes das gramíneas nos biótipos que constituem áreas de alimentação para as duas espécies de Rhytiodus.

A exemplo do que ocorreu com $S$. fasciatus, também para $R$. microlepis o item restos animais (nesta espécie constituído principalmente de microcrustáceos e ovos] ocorreu em maior freqüência na estação "alta".

A menor freqüência de algas na alimentação das três espécies estudadas, ocorreu na estação "baixa". Nesta época, de fato, não 
são observados os blocos de algas filamentosas dos locais de água calma ou mesmo ao redor ou entre as macrófitas aquáticas, coms sucede comumente nas demais estações. Este fato parece dever-se à grande turbulência de água do lago (nesta época em menor volume) que é agitada pelo vento, bem como pela falta de proteção e abrigo oferecido pela vegetação, carreada do lago para o rio nas estações "abaixando" e "baixa", ou pela ausência da vegetação semi-aquática, agora em terra firme.

Nosso estudo foi realizado num período em que a variação do nível da água do lago foi baixa $(7,79 \mathrm{~m})$ em relação à média citada acima por Lowe-McConnell. Levando-se em conta, porém, que uma acentuada descida do nível d'água dos lagos com topografia em forma de bacia, como o Janauacá, causaria inevitavelmente a morte e/ou expulsão de todo o capim aquático, é provável que, nestas condições, haja uma mudança profunda nos hábitos alimentares ou até mesmo no comportamento geral desses peixes.

Nas três espécies estudadas, os coeficientes de sobreposição alimentar calculados para as diferentes classes e tamanho, foram maiores nos indivíduos menores (tabela 7). Isso indica que os jovens tem uma alimentação básica muito semelhante modificando-se progressivamente com o crescımento, Baseado nos resultados obtidos com relação à variação ontogenética, fatores ambientais e hábitos reprodutivos (Santos, 1979) e neste trabalho, com relação ao regime alimentar, é possível concluir que as três espécies, quando jovens, apresentam o mesmo padrão geral de colorido e compartilham dos biótopos para alimentação e refúgio.

Nos estágios intermediários, houve uma diminuição dos coeficientes de sobreposição alimentar, o que parece estar relacionados com as profundas modificações dos caracteres e hábitos acima citados bem como de alguns aspectos de alometria (Santos \& Géry, em preparação]. Na classe de maiores tamanhos (260-340 mm de comprimento padrão) houve novamente um ligeiro aumento desses coeficientes, exceto entre Schizodon e R. microlepis em que se observa um valor mais ou menos igual aos dos estágios intermediários.

$\mathrm{O}$ alto valor do coeficiente de sobreposição alimentar entre os peixes menores, nas três espécies deve-se principalmente à grande freqüência do item algas. O menor coeficiente nos individuos maiores deveu-se à maior freqüência de folhas-caule na dieta de Shizodon, de algas e raízes na de $R$. microlepis e-de algas na de $R$. argenteofuscus.

Observa-se que em $S$. fasciatus o ítem restos animais ocorre em maior freqüência nos peixes menores; nas espécies de Rhytiodus, ao contrário, este item aparece em maior freqüência nos indivíduos maiores. Fruto-semente é notado apenas nos peixes acima de $180 \mathrm{~mm}$ de comprimento padrão de S. fasciatus. Este item constituiu-se principalmente de frutos e sementes de Cecropia sp., planta típica de mata secundária de várzea. Estas matas, inundadas pelas águas que transbordam dos rios na época da enchente, são importantes como refúgio e fontes de alimento para grande parte dos peixes amazônicos. Além disso, neste biótopo ocorre grande número de peixes predadores, havendo, em contrapartida, uma ausência quase total de peixes jovens de Anostomidae, os quais passam os primeiros estágios de vida na região marginal do lago, sob a proteção da cobertura dos capins aquáticos, como sucede praticamente com a maioria dos peixes amazônicos, conforme observações feitas durante várias coletas na região.

Como é grande - e continua a aumentar! - a densidade do caboclo ribeirinho nas margens dos lagos de várzea, aumenta também sua ação predatória sobre este ecossistema, manifestada principalmente pela derrubada e queimada das matas para atividades agrícolas. Este fato pode constituir uma ação danosa sobre as populações de peixes que dependem direta ou indiretamente das condições proporcionadas por este ambiente natural.

Apesar de as três espécies terem uma alimentação básica constituída de material vegetal, em todas as estações e em todos os estágios de desenvolvimento, houve certa especi- 
ficidade por determinadas partes desse material: $S$. fasciatus apresentou maior preferência pelas raizes e folha-caule dos capins aquáticos enquanto as duas espécies de Rhytiodus, por suas raizes e por algas.

Como os dentes bucais de $S$. fasciatus são muito maiores, mais grossos e robustos que os das espécies de Rhytiodus (Santos, em preparação) parece que a natureza do material vegetal tem uma certa relação com a estrutura dos dentes. Ainda a grande percentagem do item fruto-semente apresentada em S. fasciatus e de algas em Rhytiodus e o fato de $o$ ítem estomacal folha-caule apresentar-se cortado em pedaços nos indivíduos da primeira espécie, ao contrário do que ocorre nos da segunda, em que ele é raro e não apresenta essa situação, reforçam a hipótese daquela interrelação.

Inexistem informações sobre a alimentação das espécies de Rhytiodus. Ringuellet et al. (1967) citam S. fasciatus como consumidor de material vegetal e Goulding (comunicação pessoal) observou que esta espécie, no rio Machado, afluente do rio Madeira, alimenta-se principalmente de frutos de plantas de igapó. É esperado, assim, que haja variação no tipo de alimento para uma mesma espécie em diferentes biótopos ou em diferentes sistemas hidrográficos.

A bacia amazônica possui três tipos principais de águas fluviais, denominados por Sioli (1968) de águas brancas, pretas e claras com características físico-químicas e biológicas muito diferentes entre si. Intencionamos pois, no futuro, analisar as populações de Anostomidae destes diferentes tipos de águas para determinar de que maneira elas estão explorando estes ambientes, no tocante aos hábitos alimentares e reprodutivos.

\section{AgRADECIMENTOS}

Agradecemos ao Dr. Naércio A. de Menezes, pela orientação e correção do manuscrito; aos Drs. M. Goulding, Nigel Smith, T. Zaret e Sr. Sérgio Anibal, pelos comentários do texto; aos Drs. W.J. Junk, J. Géry, H. Britski, pelo apoio e sugestões.

\section{SUMMARY}

Studies of the food and feeding habits of the three species of Anostomidae most common in the "white waters" near Manaus, Schizodon fasciatus, Rhytiodus microlepis e R. argenteofuscus are presented. Data were analysed with respect to the stage of development of the fish and the regional water levels at the time of capture. The three species are herbivorous with certain degrees of preference determined by the type and structure of the vegetation ingested. There is possibly a relationship between the nature of the food ingested, the ambient conditions and certain characteristics of the digestive tract.

\section{REFERENCIAS BIBLIOGRAFICAS}

AXELROD, H.R.: EMMENS, C.W.; SCULTHORPE, D.; VORDERWINKLER, W. \& PRONEK, N.

1962 - Exotic Tropical Fishes. J.C., T.F.H. Publications, Inc., 608 p.

COBERT, P.S

1961 - The food of non-cichlid fishes in the Lake Victoria Basin, with remarks on their evolution to lacustrine conditions. Proc. Zool. Soc., London, 136: 1-101.

GEISLER, R.; KNOPPEL, H.A. \& SIOLI, H.

1975 - The ecology of freshwater fishes in Amazonia, present status and future takes for research. Anim. Res. Dev., 1: 102-119.

GERY, J.

1977 - Characoids of the world. T.F.H. Publications, Inc. Neptune city: 672 p.

GOULDING, M.

1979 - Ecologia da pesca do rio Madeira. ManausAm. CNPq-INPA. 172 p.

HARAM, O.J. \& JONES, J.W.

1971 - Some observations on the food of the gwyniad Core gonus clupeoides pennamtii Valenciennes of Llyn (Lake Bala), north Wales. J. Fish Biol., 3: 287-295.

HYNES, H.B.N.

1950 - The food of freshwater sticklebaks (Gasterosteus aculeatus) and Pygosteus pungitius with a review of methods used in studies of the food of fishes. J. Anim. Ecol., 19: 36-58.

IRMLER, U.

1978 - Matas de inundaçăo da Amazônia Central em comparação entre águas brancas e pretas. Ciên. Cult., 30 (7): 813-821.

KNOPPEL, H.A.

1970 - Food of Central Amazonian Fishes. Contribution to the nutrient ecology of Amazon Rain-Forest-Streams Amazoniana, 2 (3): 257352. 
1972 - Zur Nahrung tropisher Wusswasserfishe aus Sudamerika: Einige ausgewahite arten der Anostomidae, Curimatidae, Hemiodidae und Characidae (Pisces, Characoidei). Amazoniana, 3 (2): 231-246.

LOWE-MCCONNELL, R.H.

1964 - The fishes of the Rupununi Savana District of Britsh Guiana, South América. I. Ecological grouping of fish species and effects of the seasonal cycle on the fish. J. Linn. Soc. (Zool.), 45 (304): 103-144

1967 - Some factors affecting fish populations in amazonian waters. In: Atas do Simpósio sobre a Biota Amazônica: 7 (Conservação da Natureza e Recursos Naturais): 117-186

1969 - Speciation in tropical freshwater fishes. Biol. J. Linn. Soc., 1: 51-75.

1975 - Fish Communities in Tropical Freswater: their distribuition, ecology and evolution. London and New York, Longman. 337 p.

MARLIER, G.

1967 - Hydrobiology in the Amazon Region. In: Atas do Simpósio sobre a Biota Amazônica, 3 (Zoologia): 1.7

PETRERE Jr., M.

1977 - Pesca e esforço de pesca no Estado do Amazonas. Tese de Mestrado apresentada ao INPA-FUA. $167 p$.

1978 - Pesca e esforço de pesca no Estado do Amazonas. II. Locais, aparelhos de captura e estatísticas de desembarque. Acta Amazonica, 8 (3), Supl. 2.

RINGUELET, R.A.; ARAMBURU, R.H. \& ARAMBURU, A.L. de

1967 - Los peces argentinos de água dulce. La Plata, Comision de Investigacion Cientifica. 204 p.

ROBERTS, T.R.

1972 - Ecology of fishes in the Amazon and Congo Basins. Bull. Mus. Comp. Zool., 143 (2): $117-147$
SANTOS, G.M.

1979 - Estudo da Alimentação, Reprodução e aspectos da Sistemática de Schizodon fasciatus Agassiz, 1829 Rhytiodus microlepis Kner, 1859 e R. argenteofuscus Kner, 1859 do lago Janauacá-AM, Brasil (Osteichthyes, Characoidei, Anostomidae). Tese de Mestrado apresentada ao INPA-FUA. $91 \mathrm{p}$.

SANTOS, G.M. \& GERY, J.

s.d. - Aspectos de sistemática e morfologia de Schizodon fasciatus, Rhytiodus microlepis e R. argenteofuscus. (Osteichthyes, Characoidei, Anostomidae). (em preparaçăo).

SAUL, W.G.

1975 - An ecological study of fish at a site in upper Amazonian Ecuador. Proc. Acad. Nat. Sci. Philad., 127 (12): 93-134.

SCHMIDT, G.W.

1973 - Primary production of phytoplankton in the three types of Amazonian waters. II. the limnology of a tropical flood-plain lake in Central Amazônia (Lago do Castanho). Amazoniana, 4 (2): 139-203.

SIOLI, H.

1968 - Principal biotopes of primary production in the water of Amazônia. Proc. Symp. Recent Adv. Trop. Ecol., 591-600.

SOARES, M.G.M.

1978 - Aspectos ecológicos e alimentação dos peixes do igarapé do Porto, Aripuanã-MT Tese de Mestrado apresentada ao INPA-FUA; $77 \mathrm{p}$.

SWYNNERTON, G.H. \& WORTHINGTON, E.B.

1940 - Note on the food of fish in Haweswater (Westmorland). J. Anim. Ecol., 9: 183-187.

ZARET, T.M. \& RAND, A.S.

1971 - Competition in tropical stream fishes: support for the competitive exclusion principle. Ecology, 52 (2): 336-342.

(Aceito para publicaçăo em $12 / 03 / 80$ ) 


\begin{tabular}{|c|c|c|c|c|c|c|c|c|c|c|c|c|c|c|c|c|c|c|}
\hline $\begin{array}{ll}\text { Estaḡōes } & \text { Itens } \\
\end{array}$ & Raiz & Folha-Caule & Alga & Clcrof. & Diatom. & Cianof. & Restos Veg. & Restos Org. & Fruto-Semen. & Coarse-Litter & Chironom. & Micro-Crust. & Ovo & Esponja & Outros Artrop. & Rotif. & Molusc. & Total \\
\hline \multicolumn{19}{|c|}{ SCHIZODON FASCIATUS } \\
\hline ALTA & (15) 31,9 & (20) 42,5 & (20) 42,5 & (20) 42,5 & (15) 31,9 & (4) 8,5 & (5) 10,6 & (10) 21,3 & (16) 34,0 & (9) 19,1 & (8) 17,0 & (10) 21,3 & (1) 2,1 & (7) 14,9 & (1) 2,1 & -- & -- & (47) \\
\hline ABAIXANDO & (25) 46,3 & (12) 22,2 & (28) 51,8 & (28) 51,8 & (19) 35,2 & ( 7$)^{13,0}$ & (15) 27,8 & (27) 50,0 & (7) 13,0 & (11) 20,4 & (4) 7,4 & (2) 3,7 & -- & (1) 1,8 & -- & - & & (54) \\
\hline BAIXA & (58) 70,7 & (30) 36,6 & (49) 59,7 & (49) 59,7 & (47) 57,3 & (21) 25,6 & (29) 35,4 & (50) 61,0 & (2) 2,4 & (5) 6.1 & -- & (1) 1,2 & (1) 1,2 & (2) 2,4 & $(1) .1,2$ & (4) 4,9 & - - & (82) \\
\hline ELEVANDO & (23) 23,9 & (46) 47,9 & (42) 43,7 & (42) 43,7 & (29) 30,2 & (20) 20,8 & $(37) 38,5$ & (36) 37,5 & (2) 2,1 & (2) 2,1 & (3) 3,1 & (2) 2,1 & (2) 2,1 & (1) 1,0 & (1) 1,0 & - & -- & (96) \\
\hline Total & & & & & & & & & & & & & & & & & & (279) \\
\hline \multicolumn{19}{|c|}{ RHYTIODUS MICROLEPIS } \\
\hline ALTA & (30) 90,9 & (16) 48,5 & (33) 100 & (33) 100 & (33) 100 & (21) 63,6 & (2) 6,1 & (1) 3,0 & (1) 3,0 & (2) 6,1 & ( 7 ) 21,2 & (3) 9,1 & -- & (3) 9,1 & (1) 3,0 & - - & (3) 9,1 & ( 33) \\
\hline ABAIXANDO & (16) 64,0 & (4) 16,0 & (19) 76,0 & (19) 76,0 & (18) 72,0 & (12) 48,0 & (9) 36,0 & ( 7 ) 28,0 & (1) 4,0 & (4) 16,0 & - & - & -- & -- & - & (1) 4.0 & --1 & (25) \\
\hline BAIXA & (48) 88,9 & (4) 7.4 & (43) 79,6 & (43) 79,6 & (42) 77,8 & (30) 55,5 & (28) 51,8 & (27) 50,0 & (4) 7,4 & (1) 1,8 & $\cdots-$ & (2) 3,7 & (6) 11,1 & - & - - & (1) 1,8 & - & ( 54) \\
\hline ELEVANDO & $(55) 66,2$ & (11) 13,2 & (78) 93,9 & (78) 93,9 & (67) 80,7 & (47) 56,6 & (40) 48,1 & (32) 38,5 & (3) 3,6 & - & (7) 8.4 & (2) 2,4 & (17) 20,5 & - & -- & - & $-\cdots$ & ( 83) \\
\hline Total & & & & & & & & & & & & & & & & & & (195) \\
\hline \multicolumn{19}{|c|}{ RHYTIODUS ARGENTEOFUSCUS } \\
\hline ALTA & (1) 8,3 & $-{ }_{-}$ & (12) 100 & (12) 100 & (9) 75,0 & (5) 41,7 & - & - - & - - & - & (1) 8,3 & - - & - - & - & - & & - - & $(12)$ \\
\hline ABAIXANDO & (3) 100 & - - & (3) 100 & ( з ) 100 & (3) 100 & (2) 66,7 & -- & (1) 33,3 & -- & -- & - & - & - & - & & & - & ( 3$)$ \\
\hline BAIXA & -- & $-\ldots$ & -- & -- & -- & -- & (1) 50,0 & (2) 100 & -- & (1) 50,0 & -- & -- & $-\bar{c}$ & -- & - - & - & -- & $(2)$ \\
\hline ELEVANDO & ( 5) 31,2 & ( 2 ) 12,5 & (12) 75,0 & (12) 100 & (10) 62,5 & - - & (5) 31,2 & (10) 62,5 & -- & (1) 6,2 & ( 2) 12,5 & - & (1) 6,2 & - & - - & - & - & ( 16) \\
\hline Tota! & & & & & & & & & & & & & & & & & & ( 33 ) \\
\hline
\end{tabular}

TABELA 6 - Freqüências relativas dos ítens alimentares, calculadas pelo método dos Pontos, para as espécies estudadas, nas estações estabelecidas. Os algarismos entre parênteses indicam os pontos obtidos para cada ítem $\theta$ os seguintos, as frequências relativas correspondentes

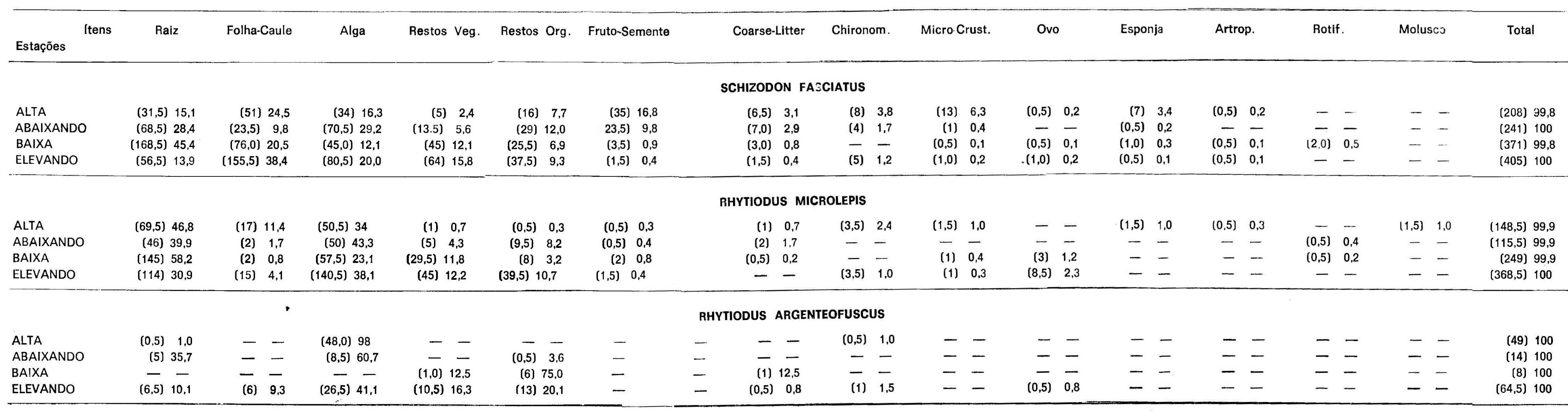


TABELA 8 - Frequêencia de Ocorrência dos ítens alimentares das espécies estudadas, em classes de diferentes tamanhos. Os algarismos entre parênteses indicam o número de peixes en que toi encontrado o item citado e os algarismos seguintes, suas freqü̈encias correspondentes

\begin{tabular}{|c|c|c|c|c|c|c|c|c|c|c|c|c|c|c|c|c|c|c|}
\hline $\begin{array}{l}\text { Comprimento } \\
\text { Padrão (mm) }\end{array}$ & Raiz & Folha-Caule & Alga & Clorof. & Diatom & Cianof. & Rest. Veg. & Rest. Org. & Fruto-Sem. & Coarse-Lit. & Chironom. & Micro-Crust. & Ovo & Esponja & Artrop. & Rotif. & Molusco & Total \\
\hline \multicolumn{19}{|c|}{ SCHIZODON FASCIATUS } \\
\hline $20 \longmapsto-100$ & (10) 20,8 & (5) 10,4 & (31) 64,6 & (31) 64,6 & (12) 25,0 & ( 9 ) 18,7 & (22) 45,8 & (33) 68,7 & (3) 6,2 & -- & ( 7) 14,6 & ( 7 ) 14,6 & - & +- & $-\quad-$ & (1) 2,1 & & (48) \\
\hline $100-180$ & (22) 46,8 & (19) 40,4 & (28) 59,6 & (28) 59,6 & (23) 48,9 & (4) 8,5 & (12) 25,5 & (20) 42,5 & (1) 2,1 & (1) 2,1 & (2) 4,2 & (1) 2,1 & - & (2) 4,2 & (1) 2,1 & (3) 6,4 & -- & ( 47) \\
\hline $180-260$ & (32) 53,3 & (23) 38,3 & (26) 43,3 & (26) 43,3 & (24) 40,0 & (11) 18,3 & (17) 28,3 & (22) 36,7 & ( 8 ) 13,3 & (11) 18,3 & (4) 6,7 & (4) 6,7 & (1) 1,7 & (4) 6.7 & (2) 3,3 & -- & -- & ( 60$)$ \\
\hline $260[-34 \rho$ & (57) 46,0 & (61) 49,2 & (54) 43,5 & (54) 43,5 & (51) 41,1 & (28) 22,6 & (35) 28,2 & (48) 38,7 & (15) 12,1 & (15) 12,1 & (2) 1,6 & (3) 2,4 & (3) 2,4 & (5) 4,0 & -- & $-\quad-$ & -- & (124) \\
\hline Total & & & & & & & & & & & & & & & & & & (279) \\
\hline \multicolumn{19}{|c|}{ RHYTIODUS MICROLEPIS } \\
\hline $20-100$ & ( 9 ) 29,0 & -- & (28) 90,3 & (28) 90,3 & (18) 58,1 & ( 9 ) 29,0 & (21) 67,7 & (21) 67,7 & - & - & - & -- & - & $-\quad-$ & & $-\ldots$ & - & (31) \\
\hline $100 \longmapsto 180$ & ( 4 ) 33,3 & (1) 8,3 & (8) 66,7 & $(8,66,7$ & ( 7) 58,3 & ( 3 ) 25,0 & (6) 50,0 & ( 5 ) 41,7 & -- & -- & -- & -- & -- & -- & -- & -- & -- & (12) \\
\hline $180 \square-260$ & (25) 96,1 & (2) 7,7 & (24) 92,3 & (24) 92,3 & (23) 88,5 & (17) 65,4 & ( 9 ) 34,6 & (13) 50,0 & -- & (3) 11,5 & (1) 3,8 & -- & (4) 15,4 & -- & -- & -- & $-\quad-$ & ( 26) \\
\hline $260-340$ & (94) 87,8 & (25) 23,4 & (95) 88,8 & (95) 88,8 & (94) 87,0 & (70) 64,8 & (38) 35,5 & (24) 22,4 & (9) 8,4 & (3) 2,8 & (11) 10,3 & ( 7 ) 6.5 & (17) 15,9 & (3) 2,8 & & (2) 1,8 & & (107) \\
\hline $340 \square-420$ & (17) 89,5 & ( 7 ) 36,8 & (18) 94,7 & (18) 94,7 & (18) 94,7 & (11) 57,9 & (5) 26,3 & ( 4 ) 21,0 & -- & (1) 5,3 & ( 2 ) 10,5 & - & ( 2 ) 10.5 & - & -- & -- & $-\ldots$ & ( 19) \\
\hline Total & & & & & & & & & & & & & & & & & & (195) \\
\hline \multicolumn{19}{|c|}{ RHYTIODUS ARGENTEOFUSCUS } \\
\hline $20 \longmapsto 100$ & (1) 14,3 & $-\quad-$ & (5) 71,4 & (5) 71,4 & ( 5 ) 71,4 & -- & (2) 28,6 & (7) 100 & - & - & - & - & $-\quad-$ & - & $-\quad-$ & & - & ( 7$)$ \\
\hline $100 \longleftarrow 180$ & (1) 50,0 & -- & ( 2$)) 100$ & (2) 100 & (2) 100 & (1) 50,0 & $\overline{1}-\overline{1}$ & - & $=-$ & $\overline{-}=$ & -- & $-\overline{62}$ & $\overline{1}-\overline{6}$ & -- & $=-$ & $=-$ & $-\quad-$ & $(2)$ \\
\hline $180-260$ & ( 2 ) 12,5 & (1) 6,2 & (14) 87,5 & (14) 87,5 & (11) 68,7 & ( 6 ) 37,5 & (2) 12,5 & $\begin{array}{l}\text { (4) } 25,0 \\
\end{array}$ & $=-$ & $\overline{(2) 250}$ & (3) 18,7 & $\begin{array}{l}\text { (1) } 6,2 \\
-\quad-\end{array}$ & (1) 6,2 & $=-$ & $=-$ & $=-$ & $=-$ & ( 16) \\
\hline $260-340$ & ( 5 ) 62,5 & (1) 12,5 & ( 6 ) 75,0 & (6) 75,0 & (4) 50,0 & -- & ( 2 ) 25,0 & (2) 25,0 & -- & & -- & -- & -- & -- & -- & -- & -- & ( 8$)$ \\
\hline Total & & & & & & & & & & & & & & & & & & (33) \\
\hline
\end{tabular}

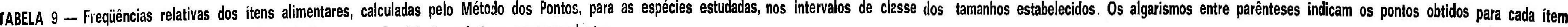
citado e os algarismos seguintes indicam suas freqüências relativas correspondentes

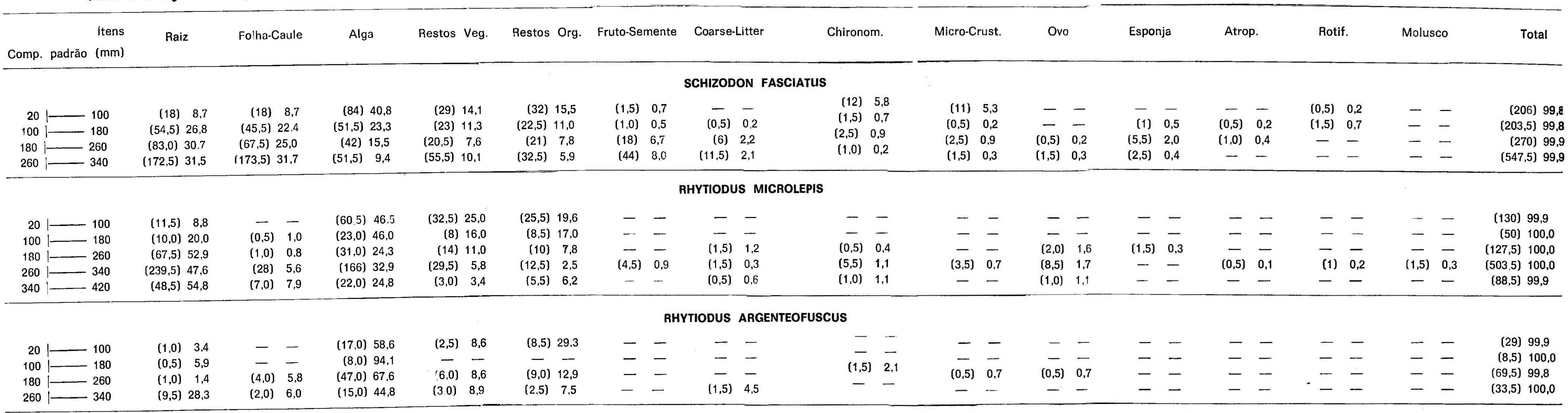

